\title{
Measurement of Human Resource Demand of Medical Institution Inspection Based on Task Analysis
}

\author{
Yan Liu ${ }^{l, 2}$ \\ Chunhong Zhou ${ }^{2}$ \\ Xiaoling Chen ${ }^{2}$ \\ Gang Chen' \\ 'School of Public Health, Fudan \\ University, Shanghai, People's Republic of \\ China; ${ }^{2}$ Health Inspection Agency of \\ Pudong New Area Health Commission, \\ Shanghai, People's Republic of China
}

\begin{abstract}
Purpose: To estimate the human resource demand of health inspection agencies to carry out the medical institution inspection function, and to provide the basis for the rational allocation of health inspection human resources.

Methods: Through policy documents review, inquiry of data from national health inspection report, Shanghai Health Inspection core business system, the basic data were collected. Based on the task analysis, the inspection functions of health inspection agency were investigated. The functional work links were analyzed, and the working time consumption was measured. The manpower needed to complete the inspection tasks of medical institutions was calculated combining with the annual functional workload and the effective working time of inspectors. Results: There were three main routine functions of medical institution inspection, namely, on-site inspection, administrative punishment, and handling of emergencies and complaints. There were 1871 medical institutions at all levels and types in Pudong New Area, with an average annual inspection frequency of 2.8 times, annual administrative penalty of 245 cases, and handling of emergencies and complaints of 330 cases. The total time required for functional work was 1656029.30 minutes, and the annual effective working time of single inspector was 66705.21 minutes. About 25 people were taken to complete the inspection tasks of medical institutions throughout the year. The number of personnel engaged in the inspection of medical institutions was 18, and the personnel gap was 7 .

Conclusion: The task analysis was an effective method to estimate the human resource demand of health inspection. In Pudong New Area, there were insufficient inspectors in medical institutions. In the case of insufficient human resource supplement, it was suggested to use technical means to improve work efficiency and save manpower investment.
\end{abstract}

Keywords: task analysis, medical institutions, health inspection, human resource demand

\section{Background}

Health inspection is a kind of health administrative law enforcement behavior which can directly act on specific citizens, legal persons and other organizations by implementing national health laws and regulations, so as to maintain public health and medical service order, protect people's health and related rights and interests. ${ }^{1}$ The health inspection agency is the executive organization of the health administrative departments, which performs the administrative law enforcement authority of medical services, environmental health, infectious diseases control, school health, occupational health on behalf of the health administrative departments.

In recent years, China's medical and health system reform continues to deepen. In Pudong New Area of Shanghai City, a lot of social capital has entered the 
medical market, resulting in not only a sharp increase in the number of medical institutions, but also a lot of new situations and new business forms, which result in unprecedented challenges on inspection. Health inspection agencies are undertaking more and more supervision tasks.

What are the functions and responsibility of medical institution inspection? How many tasks are there? How much time does it take to complete all functional tasks? How is the current time use of health inspectors? Based on the current medical institutions inspection function, is the number of inspection personnel enough? If the number of staff is insufficient, how big is the gap? All these problems have been perplexing the leaders of health inspection agency.

Working time utilization research plays a very important role in human resource planning, which can maintain and restore human resources and ensure the balance of supply and demand. ${ }^{2}$ On the basis of the balance of supply and demand, through a better understanding and analysis of the work time allocation, we can find the unreasonable factors in the work process, so as to improve work process and work efficiency. ${ }^{3}$ Taylor and Gilbraith, developed a job analysis method based on the fixed time action research on operational positions. They used time research method, action research method and workload analysis to analyze the repetitive and regular operational positions. ${ }^{4}$ The essence of task analysis method is also a study on the use of working time. Its principle is to investigate the annual workload of each work task on the basis of analyzing the main functional tasks, to decompose the process of single functional tasks, to measure the time consumption for each necessary process, and to determine the total time consumption to complete the total work task. By calculating the effective working time and work efficiency of a single person, the total number of people required to complete the organization's work tasks can be calculated, which is the human resource demanded. ${ }^{5,6}$

In order to answer the questions above, this study, taking Pudong New Area of Shanghai as an example, uses work task analysis as the method to calculate the human resources demand for medical institutions inspection, so as to promote the reasonable allocation of human resources in health inspection agencies.

\section{Method}

\section{Basic Data Investigation}

Through the inquiry of policy documents, national health inspection report, Shanghai Health Inspection core business system, the medical institutions inspection function undertaken by health inspection agencies, the main work process of single functional work task, the distribution of medical institutions, and the workload of medical institutions inspection were investigated.

\section{Collection of Task Analysis Data}

The task analysis mainly contains two parts, measurement of working time consumption and measurement of working efficiency.

\section{Working Time Measurement}

From March 24, 2015 to May 8, 2015, a total of 30 working days were selected to measure the working time of the inspectors engaged in the on-site inspection, administrative punishment, emergencies and complaints. The staff recorded the time consumption to complete a single functional task of each specialty according to the actual work situation using the working time consumption record form, and the time was calculated in minutes (see Appendix 1). The reason to select this period to carry out working time measurement, firstly is based on experience. The functional tasks and workload of health inspection agency have certain time volatility. During this period, the functional tasks are relatively full-loaded, which can cover as much as possible the functional task time consumption measurement. At the same time, due to the limitation of research time and funds, the working time measurement period can not be unlimited. Therefore, it was determined that the measuring time is 30 working days.

For the functional work task not covered in the period of working time measurement, 10 experts with health inspection experience were consulted to estimate the working time as a substitution. Expert consultation was carried out in the form of letter, instead of meeting or brainstorming, so as to ensure that the expert opinions were not easily affected by psychological factors. Base on Delphi, the number of experts is generally 10-50. In view of the relatively simple content of expert consultation in this study, the number of experts was determined to be 10 .

\section{Working Efficiency Investigation}

Taking all inspectors of health inspection agency in Pudong New Area as a whole, the sample size was calculated according to the formula: $n=\left[\left(Z_{a / 2}\right)^{2} \sigma^{2}\right] / d^{2}$, where a is 0.10 and $Z_{a / 2}$ is $1.645, \sigma$ generally chooses 0.50 and allowable error $\mathrm{D}$ is taken 
as 0.20 . Thus, the sample size $n=17$, that is, at least 17 inspectors are required to be selected for investigation. Since there are 20 internal branches in Pudong New Area Health Inspection Agency, the sample size was determined as 20 for convenience of sampling. The internal branches are divided into two categories: department and law enforcement squadron. Because the size of "department" and "law enforcement squadron" are similar, but the functions are quite different, the overall level is divided into two layers in sampling. In 10 departments and 10 squadrons, 5 squadrons and 5 departments were randomly selected by random numbers. In these 10 departments, 2 health inspectors were randomly selected from each department as the investigation object, totally 20 staff members, which accounting for $16.67 \%$ of the total number of health inspectors. The working $\log$ (See Appendix 2) was designed to record the main activities and the time of each activity in 5 working days from December 19 to December 23, 2015.

The main activities were divided and defined into four categories. "Work within the function" includes the functional work task and the work related to the functional task, "work outside the function" refers to the work beyond the scope of health inspection function, mainly including Party or Communist Youth League affairs, labor union and other related work, "affairs not directly related to work" mainly refers to rest and refreshment, "personal work" refers to the handling of personal affairs, such as making or answering personal phone calls, meeting friends, etc.

"Effective working time" is the time used for "work within the function". "Working efficiency" refers to the ratio of "effective working time" to the specified total working time.

\section{Statistical Analysis and Quality Control}

The data were collected and saved in Excel database, Spss19.0 was used for statistical analysis. The main analysis methods were descriptive analysis, comparative analysis and correlation analysis. The quality control methods included design demonstration and presurvey, modification of survey scheme and questionnaire (see Appendix 1). In order to ensure accuracy, training was conducted and repetition measurement or random sampling check was carried out.

In this study, test-retest reliability was used to test whether there were differences in the time measurement results of different staff. Different inspectors measured the single functional task working time of the same institution, and the measured values of different staff were matched, correlation coefficient was used to measure and evaluate the test-retest reliability among different staff.
Considering that there may be a gap between the time of expert consultation and the actual working time measurement, the representative institutions which have been measured on-site inspection working time consumption was selected for expert consultation, and the reliability of expert consultation time and working hours measurement time was also measured by the correlation coefficient, so as to ensure the reliability of the research data.

\section{Results}

\section{Medical Institutions Inspection Functions Analysis}

According to the results of literature review, there are six functions in medical institutions inspection, including onsite inspection, health administrative punishment, handling of emergencies and complaints, on-site sampling and detection, and major event safeguard. From a professional point of view, the medical institutions inspection covers six functional tasks on all specialties and all kinds of medical institutions. The different specialties mean the organization and personnel qualification, medical equipment, drugs, radiation diagnosis and treatment equipment and personnel, occupational disease diagnosis institutions and personnel qualification, infectious disease protection, etc. For the above-mentioned professional functions, on-site inspection, health administrative punishment, emergency and complaint handling are the three main routine functions. For research feasibility, this study only calculates the human resource needed to fulfill above three routine main functional tasks.

\section{Working Process Analysis}

The standard work flow of single functional task of on-site inspection, health administrative punishment and handling of emergencies and complaints was analyzed to determine necessary working process, which was used to guide the working time measurement.

The working process of on-site inspection includes six basic parts, preparation before on-site inspection (familiarizing with the inspection target, preparation of equipment and law enforcement documents, arrangement of vehicle and task, etc.); going to the inspection target's office; contacting the accompanying person; on-site inspection; making on-site inspection records and other law enforcement documents; return journey or going to another inspection target.

The working process of health administrative punishment includes seven basic parts, case investigation (on-site 
investigation or interrogation); collegial discussion; prior notification; statement and defense; delivery of punishment decision letter; urging and compulsion; and case closing, file making and filing.

The working process of the handling of emergencies and complaints mainly includes 10 basic parts, receiving or accepting reports; preparation before on-site investigation; going to the inspection target's office; contacting the accompanying person; on-site investigation; sampling and detecting; making documents; return journey or going to another inspection target; writing investigation report; replying.

\section{Workload Analysis}

Medical Institutions Distribution in

\section{Pudong New Area}

There are 1871 medical and related institutions in total in Pudong New Area, in which 1142 medical institutions at all levels, including 12 tertiary medical institutions, 27 secondary medical institutions and branches, 46 primary medical institutions, 131 primary branches and service stations, 6 other public institutions, 22 private general hospital, 10 Private specialized hospital, 37 private general outpatient department, 85 Private specialist outpatient department, 9 Other private institutions, 147 clinics, 287 internal medical institutions, 322 village clinics, 1 blood collection and supply institution. And there are 729 medical related institutions, including 304 radiation diagnosis and treatment institutions, 4 occupational health service institutions, and 421 pathogenic microorganism laboratories (Supplementary Tables).

\section{Routine Functional Workload of Medical Institutions Inspection}

In 2016, a total of 5247 times inspection was conducted on medical and related institutions, with the inspection coverage rate of $71.14 \%$, and the average inspection frequency was 2.80 . Two hundred and fortyfive cases of medical institutions and related administrative punishment were completed and a total of 330 emergencies and complaints were handled, with a Verification rate of $21.82 \%$. Table 1 . The three routine functional workload data were based on the year 2016 extracted from core business system, which was showed in Tables 1-3.

\section{Working Time Measurement Results}

The test-retest reliability was calculated in 32 pairs of effective measurement cases, The correlation coefficient of the working time of different inspectors at different test times to the same inspection target was 0.974 , indicating that there was a good test-retest reliability.

\section{Working Time Measurement Result of Health Inspection in Medical Institutions}

According to the analysis of the basic working process of three routine main functions, we can see both the health administrative punishment and the emergency and complaint handling contain the process of on-site inspection and investigation. Actually the on-site process is almost the same in different functional task, so the working time consumption in above two functions could be replaced by the working time consumption of the on-site inspection. We analyzed the time measurement of on-site inspection as the first step of this study, and total 221 cases were measured and analyzed. The average time consumption of each process and total time consumption are shown in Table 4.

\section{Comparison of Measured Working Time and Expert Consulted Working Time}

In view of the gap between the working time obtained from expert consultation and the actual working time measurement, the comparison of representative inspection target of each specialty was made. The average ratio between the working time measurement to the time obtained by expert consultation was 1.43 , the correlation coefficient is 0.825 , which indicates that the expert consultation time has good reliability. For the inspection targets which were not covered in the stage of working time measurement, the working time consumption was estimated by 1.43 times of the time obtained by expert consultation (see Supplementary Tables).

\section{Time Consumption Results of Single Health Inspection Functional Task in Medical Institutions}

According to the working time consumption obtained both from the actual measurement and the adjusted expert consultation, the time consumption of a single health inspection task in all types of medical institutions is shown in Table 5. 
Table I Workload of on-Site Inspection

\begin{tabular}{|l|c|c|c|c|c|}
\hline Classification & $\begin{array}{c}\text { Total Number of Targets } \\
\text { that Should be Supervised }\end{array}$ & $\begin{array}{c}\text { Number of } \\
\text { Supervised } \\
\text { Targets }\end{array}$ & $\begin{array}{c}\text { Inspection } \\
\text { Coverage Rate } \\
\text { (\%) }\end{array}$ & $\begin{array}{c}\text { Number of } \\
\text { Supervised Target } \\
\text { Frequency }\end{array}$ & $\begin{array}{c}\text { Actual } \\
\text { Inspection } \\
\text { Frequency }\end{array}$ \\
\hline Medical institutions & 1142 & 848 & 74.26 & 4635 & 3.06 \\
\hline $\begin{array}{l}\text { Radiation diagnosis and } \\
\text { treatment institutions }\end{array}$ & 304 & 253 & 83.22 & 10 & 1.16 \\
\hline $\begin{array}{l}\text { Occupational health } \\
\text { service institutions }\end{array}$ & 4 & 4 & 100.00 & 2.50 \\
\hline $\begin{array}{l}\text { Pathogenic } \\
\text { microorganism } \\
\text { laboratory }\end{array}$ & 421 & 226 & 53.68 & & 2.59 \\
\hline
\end{tabular}

Table 2 Workload of Health Administrative Penalty

\begin{tabular}{|l|c|c|c|}
\hline Classification & Number of Administrative Penalties & Composition (\%) & Cumulative (\%) \\
\hline Infectious disease prevention and control related & 28 & 11.43 & 11.43 \\
\hline Vaccine circulation and vaccination related & 2 & 6.82 & 12.24 \\
\hline Radiation diagnosis and treatment related & 16 & 15.51 & 18.78 \\
\hline Medical institution related & 38 & 0.82 & 34.29 \\
\hline Maternal and infant health related & 2 & 64.49 & 35.10 \\
\hline Medical staff related & 158 & 0.41 & 99.59 \\
\hline Mental health related & 1 & 100.00 \\
\hline
\end{tabular}

\section{Single Task Working Time Consumption} of Health Administrative Punishment and Handling Emergencies and Complaints

During the time measurement period, different health administrative punishment cases or emergencies and complaints maybe in different process, so the time measurement cases of each process except on-site inspection and investigation ranged from 7 to 76 . Using the same method as onsite inspection, we calculated average working time consumption according to the time measurement. The average working time consumption of the administrative punishment and the handling emergencies and complaints of different specialties in medical institutions are shown in Tables 6 and 7.

\section{Annual Task Basic Working Time Consumption}

"Annual task basic time consumption" is the time consumed to complete a year's functional workload without considering the number of people required to complete a single functional task. Using the working time consumption data of single functional working task and the workload data, we calculated the annual basic working time consumption of on-site inspection functional tasks is 690541.15 minutes, 41591.82 minutes of health administrative punishment and 95881.68 minutes of handling emergencies and complaints.

\section{Annual Total Time Consumption to Complete All Medical Institutions Inspection Functions}

At least two inspectors are required to carry out the single inspection functional task of medical institutions according to the laws and regulations for the reason of justice. In some large medical institutions on-site inspection, complex emergencies and complaints handling, even more inspectors are need. In this study, the number of inspectors required to implement each functional task is calculated according to the minimum standard of 2 persons. 
Table 3 Workload of Handling Emergencies and Complaints

\begin{tabular}{|l|c|c|c|c|}
\hline Classification & \multicolumn{2}{|c|}{ Results of Investigation } & \multirow{2}{*}{ Verification Rate (\%)* } \\
\cline { 2 - 4 } & Verified & Not Verified & \\
\hline Medical institution related & 15 & 59 & 20.27 \\
\hline Medical staff related & 1 & 5 & 16.67 \\
\hline Illegal termination of pregnancy and illegal sex identification of foetus & 2 & 11 & 15.38 \\
\hline Practising medicine without a licence & 54 & 183 & 22.78 \\
\hline
\end{tabular}

Notes: "'Verification rate (\%)" refers to the verified number/total number of emergencies and complaints investigated $\times 100 \%$.

The total annual time spent on the implementation of health inspection functions was calculated as following.

$\mathrm{T}=2 *(690541.15+41591.82+95881.68)=$ 1656029.30 minutes

\section{Annual Effective Working Hours of Inspectors}

The effective working time of 20 inspectors, including 9 males and 11 females, with average age of 34.71 years, selected by stratified random sampling were investigated by using the work $\log$ for 5 working days. A total of 20 valid work logs were collected.

The total specified working time of 20 inspectors in 5 working days is 7800 minutes. The 20 inspectors spent 2324 minutes on the "work within functions" in the morning and 3938 minutes in the afternoon, and total 6262 minutes in 5 working days. For the "work outside the routine function", "affairs not directly related to work" and "personal affairs",

Table 4 Results of Working Time Measurement of on-Site Inspection in Medical and Related Institutions (Minutes)

\begin{tabular}{|c|c|c|c|c|c|c|c|}
\hline Institution type & Preparation & $\begin{array}{l}\text { Going to the } \\
\text { Targets' Office }\end{array}$ & Contacting & Inspection & $\begin{array}{l}\text { Document } \\
\text { Making }\end{array}$ & $\begin{array}{l}\text { Return } \\
\text { Journey }\end{array}$ & Total \\
\hline Tertiary medical institutions & 20.00 & 43.33 & 6.67 & 228.33 & 40.00 & 33.33 & 371.67 \\
\hline $\begin{array}{l}\text { Secondary medical institutions } \\
\text { and branches }\end{array}$ & 18.33 & 32.22 & 5.22 & 127.22 & 47.78 & 22.22 & 253.00 \\
\hline Primary medical institutions & 7.78 & 25.39 & 4.52 & 31.83 & 21.66 & 22.34 & 108.98 \\
\hline $\begin{array}{l}\text { Primary branch and service } \\
\text { station }\end{array}$ & 8.00 & 9.14 & 6.67 & 13.85 & 10.59 & 12.35 & 43.22 \\
\hline Private general hospital & 13.00 & 26.60 & 6.80 & 101.10 & 47.90 & 28.50 & 223.90 \\
\hline Private specialized hospital & 11.43 & 27.14 & 21.29 & 99.71 & 52.33 & 26.00 & 230.43 \\
\hline $\begin{array}{l}\text { Private general outpatient } \\
\text { department }\end{array}$ & 12.00 & 20.92 & 6.17 & 31.08 & 24.77 & 19.15 & 110.85 \\
\hline $\begin{array}{l}\text { Private specialist outpatient } \\
\text { department }\end{array}$ & 11.43 & 27.14 & 21.29 & 99.71 & 52.33 & 26.00 & 230.43 \\
\hline Clinic & 9.60 & 15.32 & 5.40 & 24.32 & 14.65 & 12.33 & 70.08 \\
\hline Internal medicine institutions & 10.15 & 11.23 & 8.25 & 21.31 & 11.35 & 13.08 & 63.41 \\
\hline Village clinics & 8.00 & 9.14 & 6.67 & 13.85 & 10.59 & 12.35 & 43.22 \\
\hline $\begin{array}{l}\text { Blood collection and supply } \\
\text { institutions }\end{array}$ & 7.50 & 15.00 & 5.00 & 159.00 & 70.00 & 20.00 & 276.50 \\
\hline $\begin{array}{l}\text { Pathogenic microorganism } \\
\text { laboratory }\end{array}$ & 16.67 & 29.00 & 9.50 & 78.67 & 69.17 & 29.00 & 222.33 \\
\hline
\end{tabular}


Table 5 Single on-Site Inspection Task Time Consumption of Various Inspection Targets (Minutes)

\begin{tabular}{|l|l|c|}
\hline Target Classification & Sub-Classification & Time Consumption for Single On-Site Inspection Task \\
\hline Medical institutions & Tertiary medical institutions & 371.67 \\
& Secondary medical institutions and branches & 253.00 \\
& Grade I medical institutions & 108.98 \\
& Primary branch and service station & 43.22 \\
& Other public medical institutions * & 257.40 \\
& Private general hospital & 223.90 \\
& Private specialized hospital & 230.43 \\
& Private general outpatient department & 110.85 \\
& Private specialist outpatient department & 230.43 \\
& Other private medical institutions * & 357.50 \\
& Clinic & 70.08 \\
& Internal medicine institutions & 63.41 \\
& Village clinics & 43.22 \\
& Blood collection and supply institutions & 276.50 \\
\hline Medical-related institutions & Occupational health service institutions $*$ & 171.60 \\
& Radiation diagnosis and treatment institutions $*$ & 128.70 \\
& Pathogenic microorganism laboratory & 222.33 \\
\hline
\end{tabular}

Notes: *Refers to the adjusted time consumption obtained by expert consultation, and the rest refers to the time consumption obtained by working time measurement.

Table 6 Single-Task Working Time Consumption of Health Administrative Penalty (Minutes)

\begin{tabular}{|c|c|c|c|c|c|c|c|c|}
\hline Specialties & Investigation & $\begin{array}{l}\text { Collegial } \\
\text { Discussion }\end{array}$ & $\begin{array}{c}\text { Prior } \\
\text { Notification }\end{array}$ & $\begin{array}{l}\text { Statement } \\
\text { and } \\
\text { Defence }\end{array}$ & $\begin{array}{c}\text { Delivery of } \\
\text { Penalty } \\
\text { Decision } \\
\text { Letter }\end{array}$ & $\begin{array}{l}\text { Urging and } \\
\text { Compulsion }\end{array}$ & $\begin{array}{c}\text { Case } \\
\text { Closing } \\
\text { and } \\
\text { Filing }\end{array}$ & Total \\
\hline $\begin{array}{l}\text { Infectious disease } \\
\text { prevention and } \\
\text { control related }\end{array}$ & 75.33 & 18.33 & 37.00 & 10.00 & 20.00 & 0.00 & 27.00 & 187.66 \\
\hline $\begin{array}{l}\text { Vaccine circulation } \\
\text { and vaccination } \\
\text { related } *\end{array}$ & 85.80 & 28.60 & 7.15 & 42.90 & 21.45 & 0.00 & 42.90 & 228.80 \\
\hline $\begin{array}{l}\text { Radiation hygiene } \\
\text { related }\end{array}$ & 57.21 & 20.17 & 10.13 & 7.26 & 15.14 & 0.00 & 27.83 & 137.74 \\
\hline $\begin{array}{l}\text { Medical institution } \\
\text { related }\end{array}$ & 98.67 & 10.67 & 23.33 & 4.35 & 8.00 & 9.75 & 20.92 & 175.69 \\
\hline $\begin{array}{l}\text { Blood hygiene } \\
\text { related } *\end{array}$ & 68.64 & 28.60 & 11.44 & 18.59 & 25.74 & 0.00 & 22.88 & 175.89 \\
\hline $\begin{array}{l}\text { Maternal and child } \\
\text { health related } *\end{array}$ & 214.50 & 57.20 & 14.30 & 10.01 & 18.59 & 0.00 & 42.90 & 357.50 \\
\hline Medical staff related & 71.32 & 12.33 & $|7.5|$ & 27.30 & 9.18 & 0.00 & 25.37 & 163.01 \\
\hline $\begin{array}{l}\text { Mental health } \\
\text { related }\end{array}$ & 343.20 & 50.05 & 14.30 & 42.90 & 21.45 & 0.00 & 57.20 & 529.10 \\
\hline $\begin{array}{l}\text { Occupational health } \\
\text { service institution } \\
\text { related } *\end{array}$ & 214.50 & 25.74 & 14.30 & 42.90 & 12.87 & 0.00 & 28.60 & 338.91 \\
\hline
\end{tabular}

Notes: *Investigation and evidence collection refers to investigation and evidence collection unrelated to on-site inspection. 
Table 7 Single-Task Working Time Consumption for Handling Emergencies and Complaints (Minutes)

\begin{tabular}{|c|c|c|c|c|c|c|}
\hline \multirow[t]{2}{*}{ Classification } & \multirow[t]{2}{*}{ Results } & \multicolumn{5}{|c|}{ Time Consumption } \\
\hline & & $\begin{array}{l}\text { Reception and } \\
\text { Acceptance }\end{array}$ & $\begin{array}{l}\text { System } \\
\text { Input }\end{array}$ & $\begin{array}{l}\text { Investigation and Evidence } \\
\text { Collection* }\end{array}$ & $\begin{array}{c}\text { Writing } \\
\text { Investigation } \\
\text { Report }\end{array}$ & $\begin{array}{l}\text { Replying to } \\
\text { Informant }\end{array}$ \\
\hline Medication & Verified & 18.96 & 7.50 & 195.92 & 48.75 & 10.50 \\
\hline related & $\begin{array}{r}\text { Not } \\
\text { verified }\end{array}$ & 17.57 & 8.89 & 191.58 & 45.00 & 30.00 \\
\hline
\end{tabular}

Notes: *Investigation and evidence collection refers to investigation and evidence collection unrelated to on-site inspection.

the time consumption was 1538 minutes. So the "working efficiency" of single inspector is $80.3 \%$.

The "effective working days" of the whole year are the total days deducting the days of weekends, statutory holidays, paid leave, study and training, rest and recuperation. The total number of days in the whole year is 365 days, of which about 104 days are weekends, 11 days are statutory holidays, paid leave are calculated as the minimum 5 days in accordance with the regulations on paid annual leave of employees. According to the requirements of the National Health Inspection Center, each inspector needs to complete 30 class hours of training, 20 class hours of continuing education, and as public servants also need to complete 5 class hours of online training per year. All the training accumulates total of 55 class hours, which is calculated as 7 days. At the same time, every department shall complete a half-day of case discussion every two weeks, which means totally 13 days per inspector per year. According to the notice of the Ministry of health on the training program for health inspectors (2012 Edition), "primary health inspectors are required to be trained 80 class hours per year", it will cost 10 days per inspector per year. And according to Shanghai Municipal regulations, one-fourth of the total number of employees should participate in 8 days of rest and recuperation, which means 2 days for each inspector. Taking all above in consideration, it is concluded that the effective working days per inspector per year is 213 days.

According to the actual work, the daily working time of each inspector is 390 minutes, and the work efficiency is $80.3 \%$. Therefore, the effective working time of each inspector is 66705.21 minutes.

\section{Inspectors Demanded for in Medical Institutions Inspection}

According to the total annual working time consumption and the effective working time of inspectors, the number of inspectors needed to implement the medical institutions inspection function was calculated to be 24.83 , namely 25 .

\section{Discussion and Suggestion \\ Discussion}

Task Analysis is a Suitable Method to Calculate the Health Inspection Human Resources Demand

Task analysis, also known as job description research, is widely used in human resource planning. Job description can make quantitative analysis for all tasks of an organization, determine the time consumed to complete a task, the frequency of task occurrence, the difficulty degree of task and the number of operators. ${ }^{7}$ By statistical information analysis, the whole task of an organization can be accurately calculated, so as to measure the human resources required by each organization to complete all tasks. Task analysis has the characteristics of simple method principle, easy operation, and the measurement results can reflect the objective reality, and also it is scientific and reasonable..$^{7-10}$ It is especially suitable for the field of less research on human resource demand calculation, but it is kind of complicated to measure the working time of personnel. ${ }^{11}$

Task analysis is highly advocated by the academic community at present, and it has also been applied in many fields, including the analysis of the core professional ability of enterprise human resource management personnel, ${ }^{8}$ providing reference path for enterprise personnel training and cadre reserve; research on human resource allocation of coordinative health inspectors, ${ }^{9}$ especially 
widely used in nursing field because of the relatively simple working process. ${ }^{12-20}$ Due to the complexity of health inspection work task, there are few researches on the measurement of human resource demand based on task analysis. Therefore, this study explores the human resource demand of medical institution inspection by using the method of task analysis, and expresses the total amount of work task by the total time consumption of functional task, so as to accurately measure the human resource demand.

\section{The Characteristics of the Medical Institution Inspection Determine That the Implementation of Functional Task Needs Sufficient Manpower}

Health inspection is an administrative law enforcement act, it shoulders the responsibility of disease prevention and control, public health emergency handling, and major events safeguard. The inspection of medical institutions covers all the medical or medical related fields, with a very wide range. Health inspection is not only simple administrative law enforcement, but also containing a variety of connotations, such as inspection, detection, guidance, promotion, correction and treatment, etc. In the work of the medical institutions inspection, the judgment of the illegal behavior is based not only on medical knowledge, but also on the on-site detection of the environment conditions, so it has professional and technical dependence.

The inspection of medical institutions is related to life and health. With the continuous emergence of new things such as internet diagnosis and treatment, higher requirements are put forward for health inspection. The characteristics of health inspection determine that the main functional tasks need to be realized through the labor of health inspectors. Therefore, the quantity of health inspection human resources is a prerequisite. Adequate human resources allocation is conducive to the development of health inspection.

\section{Health Inspection Human Resources in Pudong New Area Health Inspection Agency are Relatively Insufficient}

This study estimates that the implementation of the three main functional task of medical institutions inspection in Pudong New Area requires 25 staff. Up to now, there are total 18 inspectors engaged in the medical institutions inspection, and the personnel gap is 7. Health inspection human resources are the most active and most important resources in all resources. ${ }^{21}$ Sufficient number of health inspectors and stable health inspection personnel team are the foundation to ensure the full implementation of functions. In this study, only three routine main functions were considered, actually the medical institutions inspection also included other functional work task such as on-site sampling and detection, major events safeguard and so on. Considering all the work tasks comprehensively, the personnel gap will be larger. At the same time, normal absence, including home leave, personal leave, sick leave, marriage leave and maternity leave, is not taken into account when calculating the effective working time of staff. And also due to the research status, the time consumption measured may be lower than the actual working condition, and the personal affair time and the time consumption of affairs not directly related to work recorded by work log will also be reduced compared with daily work status. Based on the above reasons, the actual personnel gap may be larger than the estimated.

\section{Suggestions}

Based on the current situation of insufficient human resources in medical institutions inspection, the professional and technical nature of health inspection and the dependence of human resources, in order to improve the insufficient human resources allocation and better perform health inspection duties, it is suggested to increase the number of personnel steps by step. Under the premise that the manpower cannot be filled up quickly, the measures to enhance the posts attraction and improve the incentive should be taken to maintain the team stability. In addition, we should make full use of the modern technique such as internet of things, big data, and other means, to explore health inspection with single person wearing law enforcement recorder, reduce the frequency of on-site inspection instead of online monitoring, and shorten the travel time based on GPS/GIS path planning and so on. By all these means, work efficiency can be improved and manpower can be saved.

\section{Conclusion}

Task analysis was an effective method to estimate the human resource demand of health inspection.

In Pudong New Area, there were insufficient inspectors of medical institutions. In the case of insufficient human resource supplementation, it is suggested to use technical means to improve work efficiency and save manpower investment.

\section{Data Sharing Statement}

The data of this study are available from the corresponding author on reasonable request. 


\section{Ethics Approval and Consent to Participate}

Ethical approval was obtained from the Ethics Review Committee of Health Inspection Agency of Pudong New Area Health Commission, Shanghai. Permission was obtained formally from all study hospitals. Written informed consent was obtained from study participants.

\section{Funding}

The study was funded by Shanghai Pudong New Area Health System Discipline Leader Training Program (pwrd2018-19).

\section{Disclosure}

The authors declare that they have no competing interests.

\section{References}

1. Tonggang Z. Progress and thinking of health supervision system reform and health supervision system construction. China Health Legal System. 2009;(3):4-12.

2. van HASSEL D, van der VELDEN L, de BAKKER D, et al. SMS text messaging to measure working time: the design of a time use study among general practitioners. BMC Health Serv Res. 2018;18 (1):110-131. doi:10.1186/s12913-018-2926-z

3. Abdulwahid MA, Booth A, Turner J, et al. Understanding better how emergency doctors work. Analysis of distribution of the time and activities of emergency doctors: a systematic review and critical appraisal of time and motion studies. Emergency Med J. 35 (11):692-700. doi:10.1136/emermed-2017-207107

4. Jianfeng P. Strategic Human Resource Management: Theory, Time and Frontier. January 2014. 1st. ed Beijing: China Renmin University Press; 2014.

5. Merz J, Gershuny J, Harvey AS. Measuring work-life balance using time diary data. Int J Time Use Res. 2004;1(1):I-IV.

6. Krantz-Kent R. Measuring time spent in unpaid household work results. Monthly Labor Rev. 2009;(7):46-59.
7. Min T, Shuxiang Y, Xiuyun W. Discussion on the allocation of health human resources. Chin J General Med. 2007;10(17):1478-1480.

8. Haixia L. Analysis of core professional competence of human resource management personnel in enterprises based on typical task analysis. Modern Econ Inform. 2016;(7):96.

9. Xiaoling C, Aiping G, Meifen Z, et al. Research on human resource allocation of coordinative health inspection service based on task analysis. Modern Preven Med. 2015;(13):2469-2471.

10. Wang Y, Jinfa D, Wei L. Researches on health human resource allocation methods. China Health Resources. 2006;9(6):276-277.

11. Hong W, Ming W, Yanli S, et al. Study on unit time service and its application in regional health human resource allocation. China Health Resources. 2000;3(6):283-285.

12. Huaping L, Yuxiu G, Mo L, et al. Study on the measurement method of nursing working hours. China Nurs Manage. 2007;(10):27-29.

13. Xiuxia H, Bishuang L, Yali H, et al. A study on rational allocation of human resources in ICU based on the calculation of nursing hours. Contemporary Nurses (Zhongxunzao). 2015;(07):168-170.

14. Ma D, Mei J, Zhong H. Investigation and analysis of nursing hours in maternity ward. China Nurs Manage. 2012;(04):55-57.

15. Gong K, Wenqin Y. Calculation of perioperative nursing workload and reasonable allocation of human resources for patients with cervical spondylosis. Chin PLA J Nurs. 2011;28(9):5-8.

16. Xia Y, Xiaodong X, Ziying Y, et al. Study on nursing manpower allocation in bone marrow transplantation ward based on working hours measurement. Chin J Nurs. 2016;(07):823-826.

17. Chang Y-P, H-t. K, I-c. L, et al. [The Computer Competency of Nurses in Long-Term Care Facilities and Related Factors].. Hu $\mathrm{Li}$ Za Zhi the Journal of Nursing. 2016;63(6):61-64. doi:10.6224/ JN.63.6.61

18. Shuying W. Study on calculation of outpatient nursing workload. Chin J Practical Nurs. 2009;25(23):9-12.

19. Juxia Z, Yuxia M, Lin H. Measurement of nursing hours and analysis of influencing factors in general hospital. Nurs Res. 2013;27 (27):3039-3041.

20. Wang L, Zhaoyuan S, Li Y, et al. Study on the allocation of nursing human resources in long-term care field of nursing homes. Chin J Nurs. 2016;(01):15-20.

21. Xiang H, Wang J, Gang C, et al. Analysis of human resource allocation in health inspection institutions in China. Chin $J$ Health Inspection. 2007;14(4):311-313.
Risk Management and Healthcare Policy

\section{Publish your work in this journal}

Risk Management and Healthcare Policy is an international, peerreviewed, open access journal focusing on all aspects of public health, policy, and preventative measures to promote good health and improve morbidity and mortality in the population. The journal welcomes submitted papers covering original research, basic science, clinical \& epidemiological studies, reviews and evaluations, guidelines, expert opinion and commentary, case reports and extended reports. The manuscript management system is completely online and includes a very quick and fair peer-review system, which is all easy to use. Visit http://www.dovepress.com/testimonials.php to read real quotes from published authors. 